Aletheia

ISSN: $1853-3701$

publicaciones@fahce.unlp.edu.ar

Universidad Nacional de La Plata

Argentina

\title{
Hacia un cuerpo marica: una reflexión situada sobre investigación, memoria queer/cuir, infancia sexo-disidente y trols
}

\section{Saxe, Facundo}

Hacia un cuerpo marica: una reflexión situada sobre investigación, memoria queer/cuir, infancia sexodisidente y trols

Aletheia, vol. 10, núm. 19, 2019

Universidad Nacional de La Plata, Argentina

DOI: https://doi.org/10.24215/18521606e025

Esta obra está bajo una Licencia Creative Commons Atribución-NoComercial-Compartirlgual 4.0 Internacional. 
Dossier: Memorias desde las disidencias sexo-genéricas. Preguntas incómodas para desmontar el cisexismo heterosexual.

\section{Hacia un cuerpo marica: una reflexión situada sobre investigación, memoria queer/cuir, infancia sexo-disidente y trols}

Towards a marica body: a situated reflection on research, queer memory, sexual dissident childhood and hate speech Abstract

Facundo Saxe

DOI: https://doi.org/10.24215/18521606e025

Centro de Interdisciplinario de Investigaciones en Género

- Instituto de Investigaciones en Humanidades y Ciencias

Sociales - Universidad Nacional de La Plata, Argentina

facusaxe@yahoo.com.ar

Recepción: 01 Noviembre 2019

Aprobación: 20 Noviembre 2019

Recepción: 01 Noviembre 2019

Aprobación: 20 Noviembre 2019

\section{Resumen:}

Este artículo busca construir una primera aproximación reflexiva desde categorías provenientes del pensamiento sexo-disidente y el análisis cultural a una serie de experiencias de investigación situadas y relacionadas con derivas identitarias vinculadas a la construcción de conocimiento desde perspectivas teóricas propias de la subversión sexo-genérica. Para esto se desarrollará una propuesta de escritura vinculada al concepto de interruqción (val flores) que pretende establecer relaciones entre ciertas trayectorias de investigación sobre memoria queer y representaciones culturales en el sistema científico con la posibilidad de una construcción auto-histórico-teórica (Gloria Anzaldúa) anclada en la recuperación de una enunciación sexo-disidente proveniente de la infancia marica.

PALABras CLAVE: Infancia marica, Enunciación, Disidencia sexual, Memoria queer.

\section{ABSTRACT:}

This paper presents a first reflexive approach through categories from sexual dissent and cultural analysis, to a series of situated research experiences. This issue is related to the construction of knowledge from theoretical perspectives of sex-gender subversion. For this, a writing proposal linked to the concept of interruqción (val flores) will be developed. It is intended to establish relationships between certain research trajectories on queer memory and cultural representations in the scientific system with the possibility of an auto-historia-teoria construction (Gloria Anzaldua), linked to the sexual dissent in childhood.

KEYWORDS: Marica childhood, Enunciation, Sexual dissent, Queer memory.

\section{INTRODUCCIóN}

En abril de 2019 fui víctima de algo que en un principio no entendí. En un programa de televisión de un canal de cable de noticias se burlaron del título de una ponencia de mi autoría presentada en un congreso(1). En esa emisión, a partir de la burla y las risas (enmarcadas en discursos prejuiciosos), se invalidó mi trabajo de investigación por mi apariencia en ciertas fotografías y la descripción de algunos de mis perfiles en redes sociales. Después voy a ampliar un poco toda esta cuestión, pero quería empezar con eso. Con situar algo que tiene que ver con una situación de burla, de risa, que considero asociada al odio, a un tipo específico de odio.

Eso que ocurrió en abril no era el principio de una situación, sino el grado máximo (hasta el momento) de algo que venía ocurriendo desde diciembre de 2016, cuando desde sectores conservadores (muchos afines, en ese momento, al gobierno de Mauricio Macri) comenzaron una campaña de difamación y hostigamiento a diferentes actores del sistema científico argentino con, considero, un énfasis específico en CONICET. En ese contexto, el ataque fue direccionado a las ciencias sociales y las humanidades como forma de generar argumentos cargados de discriminación y prejuicios al recorte de fondos en ciencia y técnica en Argentina(2). 
No se trata de narrar esa situación que conocemos, pero me interesa marcar ciertas coordenadas de existencia que me llevaron a pensar algunas reflexiones que quiero compartir en este texto.

Aunque no lo parezca, me interesa hablar de ciertos procesos culturales, subjetivos, pero también colectivos, que se vinculan con la construcción de una memoria desde la disidencia sexual, y también con el recuerdo pensado desde la subversión de sexo-género y, en particular, la recuperación de la infancia en el caso específico de las infancias maricas (en un devenir situado específico, asociado en una reflexión autohistórico-teórica sobre mi propia infancia marica). Para todo esto, voy a recorrer algunos principios teóricos de forma superficial a través de una dinámica escritural caótica que pretende simplemente marcar algunos interrogantes y derivas. En todo caso, en base a ciertas lecturas situadas y a algunas reflexiones, me interesa marcar algunas preguntas y colectivizar en mi escritura algunos devenires actuales de mi proceso como persona que se dedica a la investigación y que elige auto-designarse investigadora marica(3). Asimismo, este texto construye una reflexión ensayística sobre ciertos devenires marica situados en un aquí y ahora específico que no pretenden ser universales ni enunciar de forma colectiva (más allá del uso o no de algunas formas de enunciación y narración colectivas).

En lo que sigue voy a construir una deriva textual caótica, que elige el caos, la correspondencia y la relación de conceptos y experiencias como forma ensayística de pensar la reflexión y la producción de conocimiento desde las disidencias sexuales. Quizás esta dinámica escritural que parte del caos parece que no va hacia ningún lado (¿por qué debería ir?), tal vez parece algo delirante (y en algún sentido puede serlo), pero pretende construir un texto reflexivo ensayístico que se relacione con experiencias y formas de pensar(nos).

\section{INVESTIGAR MARICA}

Entonces, este texto no se ubica como un artículo de investigación en el sentido tradicional del término, sino más bien en la reflexión ensayística a partir de algunas derivas teóricas: la autohistoria-teoría de Gloria Anzaldúa (1987), una forma de reflexión autobiográfica que recupera la posibilidad de teorizar el propio recorrido vital desde posicionamientos contra-hegemónicos y subversivos; el archivo psíquico, como una de las referencias que utiliza Derrida en Mal de archivo. Una impresión freudiana (1995), para pensar ciertos restos que quedan en el archivo de recuerdos personales; además de varios de los aportes teóricos de val flores.

A partir de la posibilidad de construir una reflexión teórica mediante registros contra-hegemónicos me interesa retomar la idea de interruqción de val flores (2013), para correrme, en alguna forma (que no quiero decir que lo logre), de las modalidades habituales de producción de conocimiento en el sistema cis-heteropatriarcal. La interruqción es parte de las lógicas con las que me gustaría pensar este recorrido textual:

Interrumpir la lógica identitaria de los géneros literarios, las disciplinas académicas, los trabajos y profesiones, produce cruces narrativos, interfaces identitarias, ficciones somáticas, imaginarios híbridos, que descolocan los horizontes de lectura sostenidos bajo la promesa de un objeto delimitado y definido, ya sea desde la pedagogía, el activismo, la literatura (flores, 2013: 22).

Me gustaría pensar que, a veces, interrumpir/interrumqir(4) puede ser parte de mi intento como investigadora, de la forma en la que estoy ensayando enunciar en algunas zonas textuales de esta y otras derivas escriturales. Como ya dije, la enunciación de este texto no pretende ubicarse como verdad, ni cisheterocentrada ni verdad queer. Lo que quiere este texto es habilitar la posibilidad de reflexionar desde una voz propia, una lengua desde la que empezar a construir afectos y escrituras. Y lo digo desde mi voz personal y marica, no pretendo universalidad al respecto, si hay una búsqueda de una voz y una lengua son las mías, subjetivas, personales y maricas. Tampoco uso el término "marica" en una nueva forma de universalidad marica, no pretendo hablar en nombre de un colectivo o de todas las maricas, sólo es mi versión de ser marica en este aquí y ahora en caos y crisis. 
Me resulta muy importante hablar y enunciar escritura en primera persona en espacios (reales, públicos pero también textuales) de construcción de conocimiento situado. Porque no lo pude hacer durante mucho tiempo y creo que desde una perspectiva sexo-disidente sigue siendo muy importante que hablemos desde nuestras enunciaciones situadas. Desde ahí este ser marica, existir marica, ahora, aquí, es parte de mi experiencia de investigación y mi cuerpo en el espacio (público) científico.Actualmente me dedico a leer e investigar sobre disidencia sexual (esa categoría tan compleja) y representaciones culturales. Y me interesa avanzar sobre una reflexión a partir de cruces vitales-teóricos que piensan desde donde leemos y cómo leemos y cómo enunciamos e investigamos desde las disidencias sexuales. No tengo ninguna respuesta ni pretendo que esto sea una verdad. Sólo me hago preguntas.

Entre los temas que investigué previamente a la producción de mi tesis doctoral(5), trabajé con la cuestión de los testimonios de los llamados "hombres del triángulo rosa", en particular el caso de Heinz Heger(6), uno de los pocos sobrevivientes homosexuales a los campos de concentración del nazismo. Años después, retomé ese trabajo que cobró forma como parte de mi proyecto integral de investigación posdoctoral y que deriva en mi tema actual de investigación en CONICET, "Disidencias de sexo-género y memoria desde una perspectiva comparada en textos culturales alemanes y argentinos recientes". En ese recorrido abordé, en una serie de trabajos, los textos testimoniales más conocidos (en realidad, los únicos que quedan) vinculados a disidencias sexuales y el triángulo rosa durante el nazismo: Los hombres del triángulo rosa (Heinz Heger, 1972), Pierre Seel, deportado homosexual (Pierre Seel y Jean Le Bitoux, 1994), Aimée \& Jaguar. Una historia de amor, Berlin 1943 (Erica Fischer, 1994), Itinerario de un triángulo rosa (Rudolf Brazda y Jean-Luc Schwab, 2010), entre otros textos que tensionan entre lo testimonial y lo ficcional. Esas derivas investigativas me llevaron a avanzar sobre un trabajo comparado desde una perspectiva sexo-disidente con diferentes apariciones culturales de referencias al triángulo rosa y otros significantes en el contexto argentino, en producciones audiovisuales, historietas y literatura. En ese mismo proyecto de investigación avancé en relacionar algunas posibilidades de la categoría de memoria (desde los estudios de memoria y posmemoria) con conceptos y nociones de las teorías queer y el pensamiento sexo-disidente. En ese sentido, estos trabajos confluyeron en la idea de pensar una memoria queer situada que podríamos denominar memoria cuir o memoria cuira. Esa investigación no se encuentra cerrada y es actualmente mi tema de investigación, señalo estas cuestiones porque me interesa marcar ciertas relaciones y vínculos con una serie de experiencias a las que me voy a referir en este texto. Ese proyecto de investigación, más que nada vinculado a la aparición de la memoria cuir en representaciones ficcionales en diversos espacios geopolíticos, me llevó a reflexionar sobre determinadas cuestiones acerca de las modalidades de lectura, enunciación y construcción de conocimiento desde las disidencias sexuales.

Al trabajar con el análisis de cultura (cine, literatura, historietas, etc.) apareció una pregunta que también se ha hecho la historiadora lesbiana no binaria Canela Gavrila (2018) “ ¿cómo leemos las disidencias sexuales?”. Esto me interesa porque creo que existen derivas de identificación sexo-disidentes que piensan la cultura (tanto desde la lectura como la creación) como espacio de refugio y resistencia

\section{Discursos DE ODIO}

Volvamos ahora a la referencia que señalé en las primeras líneas, la situación de hostigamiento virtual contra las ciencias durante el período diciembre 2016 a noviembre de 2019 (que espero sea el final de esa campaña). Como decía, yo fui una de las personas atacadas en esa campaña en redes sociales y diferentes medios. ¿Qué tiene que ver esto con los puntos anteriores de esta deriva? Dos cuestiones que considero importantes para esta reflexión: primero, el inicio del proceso de hostigamiento y difamación vino justamente por mi proyecto de investigación de CONICET. El primer ataque virtual fue cuando aparecí nombrada en una nota difamatoria y cargada de prejuicios de una página llamada "la internet online" que publicaba un listado con las supuestas "veinte peores investigaciones de CONICET" (nota que luego se viralizaría en otras redes y medios gracias a usuarixs y "periodistas" de ultraderecha). Con mi proyecto de trabajo que mencionaba el 
concepto de memoria queer, ocupaba el puesto trece; segundo, el ataque se volvió sistemático y mucho más personal cuando usuarixs de redes que se dedican a los ataques virtuales (lo que comúnmente se llama trol) encontraron mis perfiles en redes sociales y algunos títulos de diferentes ponencias y trabajos que presenté en congresos y jornadas. Esos dos puntos me parecen interesantes, porque se vinculan con ciertas relaciones que quiero establecer en esta deriva textual. Un ataque en redes que toma como primer rasgo (en forma colectiva) el trabajo con memoria y disidencia sexual (por una circunstancia puramente casual, era el tema que aparece en mi perfil de investigador de CONICET), y como segundo rasgo el hostigamiento personalizado por mi visibilidad desde la disidencia sexual en mis redes sociales en las que me identifico como marica, entre otras cosas. En ese momento eran redes personales, no se trataba de redes profesionales o laborales. Durante diciembre de 2016 a enero de 2017 hubo muchos mensajes de odio de todo tipo contra diferentes investigadorxs, yo recibí en mis redes muchos ataques, principalmente por mi identificación marica, mi visibilidad en redes (fotos personales en las que aparezco dragueadx o besándome o visible de alguna forma en rasgos que esos usuarixs odiantes leían como "degenerados") y los títulos de mis ponencias que evidencian que trabajo con disidencias sexuales. Sistemáticamente en 2017 y 2018, cada tantos meses, volvía a recibir mensajes odiantes por formar parte de CONICET y utilizar la "plata de los impuestos"(7) con fines que esxs usuarixs leían como totalmente inválidos, como investigar temas de disidencia sexual desde la disidencia sexual. No quiero precisar los cientos de mensajes cargados de odio, prejuicio y homofobia en diferentes redes y en mi correo electrónico que recibí desde diciembre de 2016 a la fecha. Pero sí me interesa el hecho para continuar con esta deriva. Desde un primer momento muchos actores de mi comunidad afectiva salieron a construir redes de sostén y refugio para esos hechos de odio. Personalmente no supe reaccionar y me refugié en el silencio. Nunca supe cómo responder al odio en ningún ámbito de mi vida y hasta el 2019 estuve paralizada al respecto, al menos en mis redes sociales y en otros espacios. Pero esos mensajes me hicieron reflexionar sobre mi tarea como investigadora y me llevaron a establecer ciertas relaciones entre mi tema de investigación vinculado a la memoria queer, las representaciones culturales ficcionales o autoficcionales y el lugar de la enunciación y la visibilidad en las vidas sexo-disidentes.

Cuando en 2019 el ataque de estos usuarios y discursos odiantes llega a su grado máximo ante la exposición de mis redes personales y el título de un trabajo mío en ese noticiero de un canal de cable(8), el proceso vinculado a establecer esas relaciones terminó de aparecer, al menos en una primera aproximación. A partir de ese momento (algo que venía ocurriendo previamente pero no en el modo en el que ocurrió luego), decidí hablar, enunciar en primera persona marica como enunciaba en mis redes sociales, algo que era totalmente lógico con mi trayectoria como investigadora y mis temas de trabajo.

Creo que ese momento tuvo que ver con políticas de visibilidad y recuperación de la voz que también atravesaron los discursos vinculados a las disidencias sexuales y la voz de la subversión sexo-genérica como posibilidad de enunciación (y de vida vivible). Trabajar en la expresión de la memoria en testimonios sexodisidentes de triángulos rosa y su aparición en textos de ficción tuvo un correlato causal en pensar cómo se construyó la enunciación desde la disidencia sexual y cómo se podía recuperar el recuerdo tanto colectivo como personal. Porque esa parálisis enunciativa que sentí cuando comenzaron los ataques tenía que ver con un recuerdo personal puntual que, pensando en las derivas teóricas antes señaladas (la autohistoria y el archivo psíquico), hasta ese momento no había relacionado con el hostigamiento virtual: el bullying infantil a unx ninx marica. Quiero decir con esto, pensar la memoria queer y su imposibilidad, su carácter subterráneo durante mucho tiempo, me llevó casi de forma natural a pensar cómo enunciamos y cómo recuperar el pasado infantil de las disidencias sexuales, eso que, al menos en algunas generaciones LGBTIQ+, fue negado, reprimido, disciplinado de alguna forma. En algún sentido, creo que el odio que imposibilitó durante mucho tiempo la aparición de una memoria de la disidencia sexual, forma parte del mismo sistema odiante que no quiere enunciaciones, investigaciones e infancias pensadas desde la disidencia sexual. Al menos, y aunque no me guste ese lugar, el sentimiento de ser víctima de hostigamien to como marica adulta investigadora era muy parecido al bullying infantil por niñx marica o lo que he podido recuperar al respecto. 


\section{DE LA MEMORIA CUIR A LA INFANCIA MARICA}

Ahora, ¿cómo llegar de la memoria queer/cuir/cuira a la infancia marica? Pienso en esa correspondencia que señalaba en el punto anterior, entre tema de investigación y sensación personal, entre ataque odiante y hostigamiento infantil, en ambos casos por investigadora marica. Y pienso en cómo la memoria cuir no logró, en muchos casos, atravesar ese velo terrible de conservadurismo y represión (pensemos en, por ejemplo, la cantidad escasísima de testimonios de la disidencia sexual durante el nazismo, ¿cómo hablar después de la Segunda Guerra Mundial cuando la homosexualidad seguía siendo un delito penado con cárcel por el tristemente célebre parágrafo 175), y encuentro cierta relación entre el factor colectivo y el devenir marica subjetivo y personal. Y pienso en esas categorías que antes mencioné: la interruqción de val flores, suspender el orden lógico, racional, cisheteropatriarcal que señala que investigar, escribir, enunciar marica no es una posibilidad vital en nuestras trayectorias profesionales; la autohistoria-teoría de Gloria Anzaldúa, o ¿no hay vínculos causales entre lo que investigo y mi propia historia? ¿por qué eso que me gusta llamar "investigar marica” tiene que ver con los modos de enunciación y la teorización de fenómenos de investigación colectivos pero también subjetivos y personales; ¿qué queda en mi archivo psíquico (así como algo quedó en las memorias subterráneas de las disidencia sexual) que se relaciona con la posibilidad de enunciación, lectura e investigación desde la subversión sexo-genérica? ¿cómo se relaciona mi práctica de investigación con la infancia marica borrada, disciplinada, silenciada? Existen dos libros colectivos que retoman las expresiones vinculadas a formas de habitar la disidencia sexual en la infancia desde la voz de adultxs que enuncian sobre ese momento del pasado, ese recuerdo muchas veces disciplinado por una sociedad (y un sistema cultural, político, histórico, científico) que no ha querido durante mucho tiempo (y en muchos casos todavía no quiere) que enunciemos desde la disidencia sexo-genérica. Me refiero a Chonguitas: masculinidades de niñas (2013, compilado por valeria flores y fabi tron) y Mariconcitos Feminidades de niños, placeres de infancias (2017, compilado por Juan Manuel Burgos y Emmanuel Theumer). En el primero, val flores cierra la compilación con un texto que retoma algunas de las conceptualizaciones de Derrida sobre el archivo. Y abre su reflexión con una referencia al silencio:

Comenzar por un silencio. Por los ecos de un silencio. Por hacer hablar ese silencio. No para hacerlo callar sino para desplegarlo en sus efectos. Un silencio de una experiencia corporal y de las confrontaciones subjetivas contra los límites de las regulaciones del género. Un silencio que nos toca a tod*s, de distintas maneras y con diferentes intensidades. Pero nos toca al fin (flores, 2013: 181-182).

El silencio entre el recuerdo personal en ese archivo de restos que no se fueron del todo y el silencio de un sistema de disciplinamiento que no generó condiciones para que esas memorias (cuiras) aparezcan como legítimas. Porque esas vidas (pienso en la memoria histórica, en algunos testimonios) quedaron en el silencio, en lo subterráneo, en "memorias subterráneas" (Pollak, 2006)(9). val flores retoma a Derrida y su mal de archivo y la memoria es parte de un tejido que atraviesa lo personal y lo colectivo: "(...) el archivo opera también en la vecindad -o sinonimia- de la memoria: aquello que se guarda, que resiste al flujo de la desaparición, que por alguna razón permanece, se atesora, se cultiva, se preserva." (flores, 2013: 187). En ese sentido aparece en el libro Chonguitas: masculinidades de niñas, algo que queda en ese archivo psíquico y se resiste a desaparecer, algo que no se va, algo que "opera como un archivo de prácticas disidentes de género, un archivo del "mal” que almacena impresiones y cifra las inscripciones de la censura y la represión, la supresión y la lectura de registros desobedientes del género asignado." (flores, 2013: 187).

¿Qué hay en esos ataques de odio colectivos que empezaron en diciembre de 2016 que me remitieron al silencio que se asignó sobre mi propia infancia como niñx marica? ¿Puede ser ese un indicio para pensar una investigación vinculada a la enunciación desde la disidencia sexual y la conformación de una voz marica adulta? Si pensamos desde la deriva teórica multiforme que apareció (de forma sesgada y superficial) en las páginas anteriores (flores, Anzaldúa, Derrida) creo que sí. Porque ese disciplinamiento de la infancia de unx 
niñx marica creo que tiene una relación causal con los intentos de disciplinamiento de enunciaciones sexodisidentes en espacios que no las han aceptado tradicionalmente. En ese sentido, creo que podría existir un vínculo causal entre la investigación sobre memoria cuir en representaciones culturales y el análisis autohistórico-téorico de, en este caso, mi propia infancia marica.

Entonces, si retomamos la idea (situada, subjetiva y personal) de una infancia marica, creo que podríamos encontrar un argumento para recuperar la memoria colectiva de las disidencias sexuales y cómo construir nuestras genealogías. Pensando en los modos disciplinamiento de mi infancia como niñx marica aparece la desobediencia del género asignado como un emergente que el archivo psíquico mantuvo como un resto de esas prácticas disidentes de género infantiles. Y justamente, esas prácticas fueron parte de situaciones vinculadas a la discriminación, el hostigamiento, la violencia y la inscripción de la censura impuesta como dispositivo disciplinador. ¿Por qué molestó tanto a muchas personas que yo me identifique como investigadora marica? ¿Por qué molestaba tanto mi feminidad marica infantil? Por supuesto, está el odio, la homofobia y el prejuicio, pero, al mismo tiempo creo que hay algo de la desobediencia y cierta visibilidad que no puede aparecer con tanta facilidad en ciertos circuitos de producción de conocimiento. Porque el bullying infantil (que en mi caso es la sombra de un recuerdo intolerable) opera contra niñxs maricas que no responden a la idea de varón hegemónico y cisheterosexual. Y considero que algunas maricas se fugan de la idea de varón, se fugan de esa categoría y devienen otra cosa. El cortocircuito infantil de unx niñx marica tiene que ver con esa operación de fuga, pero existe un sistema hegemónico y cisheteropatriarcal que disciplina y reprime. Algo de ese odio que sentí en los últimos años es parte de ese otro odio con el que me golpeaban en una escuela patagónica en la ciudad de Esquel (Chubut). Porque, en determinados contextos, si unx niñx marica no quiere ser varón, muchas veces, la única opción que le deja el cisheteropatriarcado es el silencio.

Esos restos, creo que, en algunos casos, perviven en ciertos refugios culturales, en invenciones y resistencias que aparecen en los modos de apropiación y torcedura de la cultura muchas veces hegemónica, pero que desde una subjetividad infantil sexo-disidente se vuelven una posibilidad de sobrevivir, muchas veces en silencio, o en espacios que no son públicos (y muchas veces tampoco son físicos), pero que operan sobre las modalidades de lectura desde la disidencia sexo-genérica. Hay textualidades culturales que se vuelven formas vivientes de conservación de ese "archivo del mal" del que habla val flores, ese archivo sexo-subversivo que contiene textos, lecturas, refugios que, en mi caso, ayudaron a sobrevivir a esx niñx marica fugadx de la normalidad heteropatriarcal. Algo de eso me parece que aparece en textos como Camino a Auschwitz y otras historias de resistencia (2015, Julián Gorodischer y Marcos Vergara) y Notas al pie (Nacha Vollenweider, 2017), y en nuestras lecturas, en las formas de volvernos actores silenciosos de una cultura que no osó decir nuestro nombre. Desde esas lecturas se construye una especie de cuerpo cultural que conserva algo de ese archivo psíquico que, creo, vuelve a aparecer cuando hay otras condiciones vitales. Algo así como volver a hablar por primera vez en una lengua que no es la que nos disciplina en un sistema binario sexo-genérico, violento y cisheteropatriarcal.

\section{IDENTIFICACIONES INFANTILES MARICAS}

Siguiendo con el punto anterior, si en mi deriva infantil marica hubo procesos violentos de disciplinamiento que "borraron" hasta parte de mis recuerdos, ¿cómo se recupera una infancia marica que apenas queda en los recuerdos? Como señalaba antes, creo que existen formas de resistencia y refugio culturales. No creo que sea casualidad que determinadas imágenes se mantengan en el recuerdo aunque no todo su contenido. Me ha pasado que mirando una película que recordaba me había gustado mucho en mi infancia, Deathtrap (dirigida por Sidney Lumet, 1982), cuando la adulta marica la vio sintió el impacto de que recordaba casi todo excepto el beso entre los personajes interpretados por Michael Caine y Christopher Reeve(10). Algo parecido me pasa cuando miro los cómics de la Mujer Maravilla de los años ochenta desde la adulta marica, las imágenes forman parte de algo que está ahí, de cierto resto que aparece cuando la enunciación adulta 
se volvió una posibilidad, al menos en este caso personal, subjetivo y situado(11). Como niñx marica se me intentó disciplinar cualquier tipo de rasgo desobediente de cierta masculinidad hegemónica, pero ese disciplinamiento no implicó la pérdida de esos rasgos, algo de esa fuga del género asignado queda en el archivo psíquico para retornar en otros momentos, como recuerdos que irrumpen en la vida adulta, recuerdos que muchas veces apenas son restos, pero que se corresponden con la posibilidad de construir una vida marica adulta.

Asimismo, algunas maricas, a veces, han ocupado un "no-lugar"(12), fuera de la visibilidad y el espacio público, sin infancia posible. Creo que es muy interesante pensar lo que ocurre con el disciplinamiento de la feminidad en las identificaciones maricas que tensionan el binarismo sexo-genérico varón-mujer. ¿Por qué se disciplina la feminidad en lxs niñxs marica? ¿Qué resultado tiene? ¿Qué efectos tiene? ¿Cómo se recupera, por ejemplo, la capacidad de enunciación marica cuando el silencio es la única opción de supervivencia? Porque en esas derivas maricas infantiles las identificaciones torcidas, las lecturas torcidas, funcionan como espacios de fuga y resistencia. Como en el ejemplo que antes mencioné, en mi deriva marica como lectora de la historieta de la Mujer Maravilla, no estaba simplemente ante un personaje que me gustaba, quería ser la Mujer Maravilla. Algo parecido me pasó como marica de baja estatura con Dana Scully, la agente del FBI de la serie The X-files (interpretada por Gillian Anderson) Porque como niñx marica preadolescente me sentía muy identificada con Dana Scully, y no se trataba simplemente de atracción o interés, yo quería ser Dana Scully. ¿Qué masculinidad queda en unx niñx marica que quiere ser la Mujer Maravilla, She-ra o la agente Scully? Algo de eso tiene que ver con mantener la fuga de unx niñx marica del sistema de normalidad binario y heteronormativo (Hegarty, 2009). Esta idea de la infancia marica como desobediencia del binarismo sexogenérico asignado creo que puede ser parte de un sistema de relaciones y retroalimentaciones para pensar que algunas maricas no son varones. Esa idea genera muchas resistencias en determinados grupos, pero no se trata de hablar de todas las identificaciones maricas, la estoy pensando simplemente en un aquí y ahora personal, situado y subjetivo, relacionado estrictamente con mi devenir marica y la recuperación de una infancia marica y una forma de enunciación en el presente desde la disidencia sexual. En ese sentido, la lectura opera como un dispositivo de refugio de ciertos modos sexo-disidentes de habitar los cuerpos. Así como pueden aparecer películas, literatura, historietas que operan como espacios habilitadores de esa infancia no vivida o esa vida no vivible (a veces por lecturas entre líneas, otras veces torciendo el objeto cisheteronormado), también creo que hay posibilidades teóricas de pensar esas fugas (en mi caso una fuga marica) del régimen heterosexual.

No quiere decir esto que estoy proponiendo una compulsión no binaria ni pretendo que todas las maricas se identifiquen por fuera de la identidad varón. Tampoco me interesa que todxs se relacionen con la masculinidad como yo. Pero tampoco creo que la masculinidad sea algo exclusivo de los varones, cis, trans, hetero, gays, etc. Así como val flores dice sobre la masculinidad lesbiana, pienso esta deriva:

Estas reflexiones no significan escribir contra la feminidad ni contra quienes la encarnan desde un deseo lésbico, sino asomar a comprender cómo aún hoy la distorsión performativa de la feminidad y la masculinidad normativa, con el asalto a la coherencia de los opuestos de género, provoca en el ámbito educativo la activación del pánico sexual (flores, 2017: 63).

Quizás se trata de repensar los lugares que habitamos, más allá de identificaciones binarias o no, la construcción de jerarquías de conocimiento puede ser una nueva forma de disciplinamiento del sistema que nos reprimió durante mucho tiempo. Como dice Atilio Rubino:

Se trata quizá de cuestionar nuestras identidades y nuestras voces, de reconocernos sujetxs atravesadxs por dispositivos de poder que nos delimitan dentro de lo humano. Quienes fuimos asignadxs como varones podemos quizás renegar de nuestra masculinidad, devenir confusxs, difusxs. Cuestionar y también renegar de nuestra (supuesta) humanidad (Rubino, 2018: 147). 


\section{UN SISTEMA DE DISTURBIOS}

Esta deriva vinculada a pensar una infancia y una identificación marica no binaria creo que tiene una relación con mi trayectoria de investigación, porque creo que, si pensamos de forma colectiva y comunitaria, la memoria de la disidencia sexual muchas veces se encuentra en los restos, en las represiones, en los disciplinamientos. Y ahí, así como en la infancia sexo-disidente puede operar la lectura como espacio de refugio y resistencia, creo que ciertas apariciones culturales (en muchos casos ficcionales) construyen esa memoria de la que sólo nos quedan restos. Pienso en libros como

El sótano de San Telmo. Una barricada proletaria para el deseo lésbico en los '70 (2015, valeria flores) y Fichados. Crónicas de amores clandestinos (2017, Cristian Prieto), que, desde la teoría, la reelaboración creativa, la reflexión autobiográfica, construyen algo de lo que muchas veces no hubo enunciación ni testimonio en primera persona. Cuando no hay texto o el texto está muy lejos de conservar algo de lo que se enunció en una realidad del pasado (pienso una vez más en "los hombres del triángulo rosa", pero también en la disidencia sexual en otros momentos del pasado de la humanidad y nuestro país), algunas formas culturales como la literatura ocupan ese "no-lugar" para recuperar visibilidad, enunciación, vida y cuerpo (textual). Por supuesto que todo esto se trata simplemente de pensar algunas preguntas y puntos de partida.

Creo que pensar nuestras infancias desde la enunciación de la disidencia sexual, así como la memoria sexodisidente, pueden formar parte de mirar la subversión sexo-genérica como una constelación, un sistema de disturbios que contamina la normalidad cisheteropatriarcal. Al respecto, me interesan las palabras de val flores sobre la disidencia sexual:

La disidencia sexual no es un conjunto de contenidos para aplicar, sino una multitud de dinámicas metodológicas carroñeras, porque trabaja con los desechos disciplinares y se nutre de saberes y experiencias que no están autorizadas ni consolidadas, sino más bien abiertas a las errancias crítico-creativas de sus inestables y desvariados imaginarios sexuales. (flores, 2018: 155)

En este momento pienso la disidencia sexual como una posibilidad fluida, tóxica, en contradicción y tensión, pienso la disidencia sexual como una forma creativa de construir un archivo del caos personal, subjetivo, sexo-subversivo y creativo tanto en la lectura como en la escritura y en la investigación. Todo este caos es sólo una forma, una versión para pensar el sistema de disturbios sexo-disidentes, para ir contra la idea de la normalidad social, científica y escritural-lectora como ficción disciplinadora. Creo que la lectura torcida está en la base de las disidencias sexuales, sólo que muchas veces la reprimen y disciplinan. Porque pensar nuestras lecturas es pensar nuestras formas de enunciación, es intentar desarmar es lengua con la que nos enseñaron a callar. Por eso creo que cruzar memoria, recuerdo, enunciación y auto-historia-teoría pueden volverse dispositivos de teorización sexo-subversiva que contaminan esas ficciones disciplinadoras. Y contaminan desde la confrontación de esos discursos que buscan disciplinar, reprimir y exterminar la visibilidad política sexo-disidente como herramienta de posicionamiento contra los mecanismos conservadores y las dinámicas de la corrección política del sistema cultural cis-hetero-patriarcal.

Ciertas formas visibles de habitar espacios (retomando las primeras oraciones de este texto) que subvierten los órdenes habituales (y muchas veces prejuiciosos) no son cosas que le agraden a muchas personas de las que me han escrito mensajes cargados de odio. Cuando comenzó la campaña de difamación me paralicé. Cuando dieron a conocer mis redes en la televisión lo primero que me dio todo eso fue pánico. Pero después también pensé en otras cosas. Creo que además de odio, también hay algo de pudor y vergüenza en todos esos discursos odiantes, de cómo aparece esa persona, esa marica, en CONICET, en la ciencia argentina y cómo se muestra de esa forma en sus redes (como dije antes, dragueada, besándome, cosas así). Creo que la visibilidad sexo-política de las disidencias sexuales tiene que ver con recuperar la capacidad de enunciar y de mostrarse como posibilidades vitales, en algún sentido de retomar todo eso que, a veces, quedó como resto en el archivo del mal y en nuestras lecturas y nuestros textos. En alguna forma, recuperar el cuerpo marica, ese cuerpo textual que me/nos permitió sobrevivir en una sociedad que me/nos quería confinada(s) al silencio 
y la represión. Y eso nos ayuda a construir vidas vivibles, porque la visibilidad sexo-disidente, en mi caso la visibilidad marica no binaria, en el espacio visible, público, científico, tensiona y genera violencias en muchas personas llenas de odio y prejuicios pero también ocurre otra cosa, cuando se recupera el cuerpo marica y se vuelve visibilidad y enunciación hay algo que cambia. Porque creo que la disidencia sexual cuando es visible, pública, nos sana. Nos ayuda a construir memorias cuiras colectivas y memorias personales de lo borrado, lo amputado, recuerdos que enuncian sobre el silencio de un pasado que no nos quiso vivas y desobedientes.

Para concluir, vuelvo a lo que ya señalé antes, nada de esto se pretende como una verdad ni como una definición, es una deriva, un viaje personal, un desvío del camino indicado por el horizonte de la corrección política. Porque las disidencias sexuales somos visibles en muchos espacios y parece que ciertas formas de hablar, de escribir, de moverse en una sociedad y en un sistema académico científico (y pensando en todas las que no están en este sistema) a muchas de esas personas discriminadoras y prejuiciosas les da mucho odio y pánico. A mí me gusta pensar ese pánico como miedo a que se descubra que detrás de todo ese odio no hay nada. Y ahí tenemos algo que nos mueve, porque del lado de las disidencias sexuales hay placer, goce, ganas de escribir, de leer y de abrirnos y dilatarnos como ese primer día que pudimos hablar y enunciar. Porque de algo sí estoy segura, de que sea como sea ya no hay posibilidad de volver a callarnos.

\section{REFERENCIAS}

Anzaldúa, G. (1987). Borderlands/La Frontera. The New Mestiza. San Francisco: aunt lute books.

Burgos, J. M.; Theumer, E. (comp.). (2017). Mariconcitos Feminidades de niños, placeres de infancias. Disponible en: $\mathrm{h}$ ttps://mariconcitos2017.wixsite.com/mariconcitos/descarga

Curia, D. (2019). "Pegarle a un puto que investiga cosas de putos fue una vía para agraviar al Conicet". 2019, abril, 21. Página/12. Buenos Aires. Disponible en: https://www.pagina12.com.ar/188809-pegarle-a-un-puto-que-in vestiga-cosas-de-putos-fue-una-via-p

Derrida, J. (1995 [1997]). Mal de archivo. Una impresión freudiana. Madrid: Trotta.

Fischer, E. (1994). Aimée y Jaguar. Una historia de amor, Berlín 1943. Barcelona: Seix Barral.

flores, val. (2013). interruqciones. ensayos de poética activista. escritura, política, pedagogía. Neuquén: La Mondonga Dark.

flores, val. (2014). El sótano de San Telmo. Una barricada proletaria para el deseo lésbico en los '70. Buenos Aires: Madreselva.

flores, val. (2017). "Masculinidades lésbicas, pedagogías de feminización y pánico sexual: apuntes de una maestra prófuga”. En Maristany, J.; Peralta, J. Cuerpos minados. Masculinidades en Argentina. La Plata: EDULP. p. 51-66.

flores, val. (2018). “Esporas de indisciplina. Pedagogías trastornadas y metodologías queer”. En: VVAA. Pedagogías Transgresoras II. Sauce Viejo: Bocavulvaria Ediciones. p. 139-208.

flores, val. (2018). "Pedagogías del deseo. Desheterosexualizar el conocimiento o ¿es posible hacer de la danza una experiencia de (des)generización?”. En XI Congreso de Danzas, Educación-Diversidad-Escena. La Plata. Disponible en: https://escritoshereticos.blogspot.com/2018/09/?view=sidebar

flores, val; tron, f. (comp.). (2013). Chonguitas: masculinidades de niñas. Neuquén: La Mondonga dark.

Gavrila, C. (2018). "no mentimos, agrandamos mundos pequeños". En Conversatorio Lecturas torcidas y descolonización del saber ¿la disidencia sexual en llamas?, 21 de octubre de 2018, La Plata.

Gorodischer, J., Vergara, M. (2015). Camino a Auschwitz y otras historias de resistencia. Buenos Aires: Emecé.

Hegarty, P. (2009). “Queerying Lesbian and Gay Psychology's ‘Coming of Age’: Was the Past Just Kids' Stuff?”. En Giffney, N.; O’Rourke, M. (eds.). The Ashgate Research Companion to Queer Theory. Nueva York. Routledge. p. 311-328.

Heger, H. (2002 [1972]). Los hombres del triángulo rosa. Memorias de un homosexual en los campos de concentración nazis. Madrid: Amaranto. 
Lenci, Laura (2019). “Usos y abusos de las ciencias humanas y sociales. Algunas batallas por los sentidos”. En Brugaletta, F., González Canosa, M., Starcenbaum, M. y Welschinger, N. (Eds.). (2019). La politica cientifica en disputa: diagnósticos y propuestas frente a su reorientación regresiva. La Plata: FaHCE-UNLP/Buenos Aires: CLACSO. p. 134-142. Disponible en: https://www.libros.fahce.unlp.edu.ar/index.php/libros/catalog/book/139

Piovani, J. (2019). "Sobre la utilidad de las ciencias sociales en tiempos de neoliberalismo y posverdad". En Brugaletta, F., González Canosa, M., Starcenbaum, M. y Welschinger, N. (Eds.). (2019). La politica cientifica en disputa: diagnósticos y propuestas frente a su reorientación regresiva. La Plata: FaHCE-UNLP/Buenos Aires: CLACSO. p. 115-133. Disponible en: https://www.libros.fahce.unlp.edu.ar/index.php/libros/catalog/book/139

Pollak, M. (2006). Memoria, olvido, silencio. La producción social de identidades frente a situaciones límite. La Plata: Al margen.

Prieto, C. (2017). Fichados. Crónicas de amores clandestinos. La Plata: Pixel.

Rubino, A. (2018). "Reseña de Cuerpos Minados. Masculinidades en Argentina”. Anclajes. Vol. XXIII, No 3, p. $145-147$.

Saxe, F. (2012). “Testimonios austríacos sobre los campos de concentración: Heinz Heger y los hombres del triángulo rosa". En Vedda, M. (ed.) Jura Soyfer en el nuevo mundo. Viena: INST-Verlag/Jura Soyfer Gesselschfat. p. 66-72.

Saxe, F. (2014). Representación transnacional de las sexualidades disidentes en textos culturales alemanes y españoles recientes (1987-2012). Tesis doctoral en letras. Facultad de Humanidades y Ciencias de la Educación, Universidad Nacional de La Plata. Disponible en http://hdl.handle.net/10915/35873.

Saxe, Facundo (2018). "La trampa mortal: derivas maricas de la disidencia sexual en la producción de conocimiento científico al recuerdo infantil de un beso". Etcétera. Revista Del Area De Ciencias Sociales Del CIFFyH. No 3. p. 1-26. Disponible en https://revistas.unc.edu.ar/index.php/etcetera/article/view/22591.

Saxe, F. (2019). "Historieta anal: cuando el cómic nos abre el culo (y nos gusta)". Revista Kamandi. Disponible en: ht tp://www.revistakamandi.com/2019/10/15/historieta-anal-cuando-el-comic-nos-abre-el-culo-y-nos-gusta/

Schwab, J.; Brazda, R. (2011). Itinerario de un triángulo rosa. El último superviviente deportado por homosexual. Madrid: Alianza.

Seel, P.; Le Bitoux, J. (2001 [1994]). Pierre Seel. Deportado homosexual. Barcelona: Bellaterra.

Vollenweider, N. (2017). Notas al pie. Buenos Aires: Maten al Mensajero.

\section{Notas}

1 Cuyo título y resumen están disponibles, como gran parte de mi producción de investigación en mi perfil de CONICET en la página web: https://www.conicet.gov.ar/

$2 \mathrm{Al}$ respecto cf. Piovani, "Sobre la utilidad de las ciencias sociales en tiempos de neoliberalismo y posverdad" (2019) y Lenci, "Usos y abusos de las ciencias humanas y sociales. Algunas batallas por los sentidos" (2019).

3 Voy a utilizar la x como posibilidad de escritura no binaria para algunas marcas genéricas del lenguaje y el femenino para mi adscripción a una identificación marica (personal y subjetiva).

4 La noción de interrupción/interruqción es desarrollada por val flores en su libro Interruqciones. ensayos de poética activista. escritura, politica, pedagogía (2013).

5 Titulada Representación transnacional de las sexualidades disidentes en textos culturales alemanes y españoles recientes (1987-2012) y defendida en abril de 2014.

6 Cf. Saxe, "Testimonios austríacos sobre los campos de concentración: Heinz Heger y los hombres del triángulo rosa" (2012).

7 La expresión "con la plata de mis impuestos" se volvió habitual en lxs usuarixs troles que difamaron y atacaron a diferentes científicxs a partir de 2016 a la fecha. En 2019, a partir del análisis de esa frase y la circulación de mensajes de odio difamatorios en redes sociales llevamos adelante junto a Agustín Liarte y Cecilia Díaz el taller “"Con la plata de mis impuestos”: Investigación, indignación y legitimación socio-cultural” en el marco de las "II Jornadas de Jóvenes Investigador*s: Producir, inventar, comunicar saber(es)”, realizadas en la Universidad Nacional de Córdoba.

8 Considero que el disparador puede haber sido la sucesión de correos electrónicos odiantes y discriminatorios, al respecto la nota de Dolores Curia en Página/12: "Pegarle a un puto que investiga cosas de putos fue una vía para agraviar al Conicet" (21/04/2019). 
9 Creo que el concepto de Michael Pollak es útil para pensar qué ocurre con ciertas formas de la memoria: “(...) esas memorias subterráneas prosiguen su trabajo de subversión en silencio y de manera casi imperceptible afloran en momentos de crisis a través de sobresaltos bruscos y exacerbados. La memoria en disputa." (Pollak, 2006: 18).

10 Trabajé sobre esa cuestión en el artículo "La trampa mortal: derivas maricas de la disidencia sexual en la producción de conocimiento científico al recuerdo infantil de un beso" (2018).

$11 \mathrm{Al}$ respecto se puede consultar el texto (que fue del disparador para los ataques de odio a partir de abril 2019) "Historieta anal: cuando el cómic nos abre el culo (y nos gusta)", en el que profundizo sobre esas ideas.

12 Tomo la idea de "no-lugar" de cita que realiza val flores a Lacombe para referirse a los estudios sobre masculinidades y la ausencia de las masculinidades lesbianas: "Escasean los estudios sobre las masculinidades desligadas de cuerpos de hombre, y en general, éstos se concentran en cuerpos de varones, lo que tiene como efecto performativo en la industria académica, seguir confiscando la masculinidad a los cuerpos y sexos "apropiados. Las masculinidades encarnadas en cuerpos que hemos rechazado, desistido o resistido los procesos de feminidad obligatoria, abriendo y posibilitando diferentes espacios identitarios, permanecemos invisibilizadas, silenciadas y relegadas a un "no-lugar" (Lacombe, 2013)." (flores, 2018: 1-2).

\section{BY-NC-SA}

